\title{
Testing for and Removing Bias in the Seasonally Adjusted Unemployment Series
}

IN EACH POSTWAR recession the official seasonal adjustment of the unemployment statistics has been called into question. The official procedure adjusts the major demographic components of the volatile monthly unemployment series by given percentages that change little from year to year. ${ }^{1}$ This suspect multiplicative model remains basically in command, but the Bureau of Labor Statistics now issues alternative estimates including those based on additive and "residual" models of seasonal correction. ${ }^{2}$ The unofficial additive model uses absolute monthly adjustments to unemployment that also change only slightly each year. The estimate of seasonally adjusted unemployment from the unofficial residual model is then the difference between the relatively stable employment and labor-force series, after each is adjusted by the official multiplicative procedure. These alternative

Note: I am grateful to $\mathrm{K}$. Wendy Holt for valuable suggestions and computational assistance, to Christine C. De Fontenay and Joseph Tu for programming advice, and Thomas J. Plewes of the U.S. Bureau of Labor Statistics for generous cooperation.

1. Beginning with 1970 , additive estimates for the 16-19-year age group have been used.

2. Currently in use is the X-11 method, which is primarily multiplicative. For a description of this method, see U.S. Bureau of the Census, The X-11 Variant of the Census Method II Seasonal Adjustment Program, Technical Paper 15, 1967 revision (Government Printing Office, 1967). 
Table 1. Official Unemployment Rate and Three Estimates of the Seasonally Adjusted Rate, Selected Months, 1975 and 1976

Percent

\begin{tabular}{|c|c|c|c|c|}
\hline \multirow{2}{*}{$\begin{array}{l}\text { Year and } \\
\text { month }\end{array}$} & \multirow[b]{2}{*}{ Unadjusted } & \multicolumn{3}{|c|}{ Adjusted } \\
\hline & & Official & Additive & Residual \\
\hline \multicolumn{5}{|l|}{1975} \\
\hline February & 9.1 & 8.0 & 8.4 & 8.4 \\
\hline May & 8.3 & 8.9 & 8.7 & 8.7 \\
\hline October & 7.8 & 8.6 & 8.4 & 8.4 \\
\hline \multicolumn{5}{|l|}{1976} \\
\hline February & 8.7 & 7.6 & 7.9 & 7.9 \\
\hline
\end{tabular}

Source: "Statement of Julius Shiskin, Commissioner of Labor Statistics" (paper delivered before the Joint Economic Committee, United States Congress, March 5, 1976; processed), table 1.

estimates of seasonally adjusted unemployment continue to contradict the official series, just as they did in previous recessions. ${ }^{3}$

The contradictory answers given by the various models are illustrated in table 1 for months of high seasonality during the current recession. The unofficial additive and residual rates, usually very close, happen to be identical for these months. Both showed only a 0.3 point rise between February and May 1975 compared with the 0.9 point jump in the official rate. Thus, the official rate indicated that unemployment rose over onehalf million more than the other estimates suggested. Between February and October, according to the official rate, unemployment worsened by 0.6 point, while the others showed no net change.

After October, the difference went the other way, as the official rate showed a half-point greater improvement by February. This sharp improvement reflected in the official statistic was acclaimed in the press; but between February and October 1976, the official rate will show less improvement than the other two will. For example, if the unofficial rates should register only a half-point decline the official rate will suggest a stalling of the recovery. Although the official rate differs systematically from the others, unfortunately there is no a priori basis for choosing between them.

These recent discrepancies in the alternative rates are not exactly earthshaking from a long-run perspective. Yet, in recessions, with rapidly rising

3. Analogous discrepancies have appeared during periods of low unemployment, but have attracted little attention. 
unemployment, considerable attention is invariably paid to month-tomonth changes in this statistic; and it is just at such times that confusing, contradictory, estimates appear. In the event of an especially severe rise in unemployment, the official seasonal-adjustment procedure could break down completely, as it did in the thirties. ${ }^{4}$ At such times, it is especially difficult for a government to change methods.

This paper applies a regression model first proposed in 1962 to the much longer series now available; two periods are used, one beginning with 1948 and the other with 1967. It generalizes the traditional approach to seasonal adjustment in order to test for an apparent bias and to produce an alternative estimate free of bias. The bias in the official aggregate unemployment rate apparently persists. The additive alternative also shows signs of bias, although a smaller one and in the opposite direction. The residual reveals no appreciable bias, but this is a tentative finding.

\section{The Continuing Controversy}

The official seasonal adjustment of the unemployment level and rate has been criticized on both intuitive and statistical grounds. ${ }^{5}$

First, a given percentage correction of the rate is difficult to square with the commonsense conception of seasonal change. For example, the raw rate rose from 5.5 to 9.1 percent between October 1974 and February 1975. The official adjustment discounted more than half of the rise-1.9 points, or about 1.5 million workers-as seasonal. One year before, virtually the same percentage correction was applied to a lower unemployment rate; hence the seasonal rise in that interval was put at only 1.1 pointsabout a million workers. Presumably, seasonal adjustment is intended to abstract from short-run changes due to relatively predictable weather and institutional arrangements. Why, then, should the effects of these factors be assumed to rise with the level of the series? Intuitively, one might even expect the seasonal climb to be absolutely smaller, the higher the level of

4. Canadian estimates are plagued with even greater seasonality. Between November 1957 and February 1958, as the economy sank rapidly into a severe recession, the number of unemployed, as measured by the official adjusted series, posted an 8 percent decline.

5. The criticism applies to use of a virtually fixed percentage correction to adjust any volatile time series. 
unemployment; with fewer employed, fewer can become unemployed due to cold weather and other such factors.

Experts in the Bureau of Labor Statistics themselves expressed doubts about the percentage correction of volatile series many years ago: "The present method of adjustment is not entirely satisfactory for adjusting monthly changes in unemployment during periods of recession when unemployment is rising sharply, because the seasonal pattern is expressed as a percentage of the series itself." They added that under certain circumstances this percentage method will "tend to overadjust when unemployment is unusually high." 6 With the onslaught of the current recession, the question was raised again. In early 1975, the Commissioner of the Bureau of Labor Statistics called for a thorough evaluation of the procedures. However, after considerable statistical analysis, apparently the multiplicative model will be retained for most demographic components, including the major ones.

Second, it was noted long ago that the sum of seasonally adjusted unemployment and employment often disagreed substantially with the independently adjusted labor force. Reacting to this discrepancy, some suggested that a "residual," representing the difference between the adjusted labor force and adjusted employment, would be a better estimate of adjusted unemployment. The assumption was that the application of the multiplicative model to these relatively stable series would give more reliable results. At one point a statistical test supported this view, while pointing to a bias in the official series. ${ }^{7}$ The hypothesis was that when unemployment is unusually high, the multiplicative model tends to overadjust the rate: when the seasonal factor is greater than unity, as in winter, the method overadjusts downward; when the factor is less than unity, it overadjusts upward. This hypothesis was supported by a negative correlation between the first differences of the official adjusted series in such periods and the first differences of the seasonal factors. A positive correlation was expected and found for months during which unemployment was unusually low. The residual measure showed no significant evidence of this kind of bias.

6. Morton S. Raff and Robert L. Stein, "New Seasonal Adjustment Factors for Labor Force Components," Monthly Labor Review, vol. 83 (August 1960), p. 827.

7. John A. Brittain, "A Bias in the Seasonally Adjusted Unemployment Series and a Suggested Alternative," Review of Economics and Statistics, vol. 41 (November 1959), pp. 405-11. 
Regression analysis has also been used to test alternative methods. One approach is to regress the estimated "seasonal-irregular" on "trend-cycle" components for each month separately. This approach assumes that any given movement is composed of elements reflecting the long-term trend, seasonal factors, and irregular forces, and that once these are removed, what remains is the relevant change for that month. It was assumed that a significant constant term and insignificant slope would indicate an additive seasonal pattern; the reverse would point to a multiplicative relationship. This test appears to have more than its share of problems. ${ }^{8}$

\section{A Model of Seasonal Factors with Varying Amplitude}

Another regression model can be used to estimate the appropriate variation of the amplitude of seasonal factors with the level of the series to be adjusted. ${ }^{9}$ For the period July 1948 through March 1961, it showed a bias in the official series and no significant bias in the residual estimate. A new method of estimation has been adopted here, but the same basic model will be applied to data from January 1948 through February 1976, and to the shorter series beginning with 1967 when the official X-11 method was introduced. The iterative estimation procedure adopted generates from the adjusted series (and its implied seasonal factors) a new adjusted series that at least is unbiased with respect to the criterion to be specified.

The standard moving-average procedure derives what are assumed to be relatively stable monthly seasonal factors, or multipliers, that are then divided into the raw data to obtain a "seasonally adjusted" series. The proposed alternative generalizes the traditional multiplicative model to admit variation in the amplitude of the seasonal factor. The ultimate

8. The data available for a given month are generally inadequate for statistical analysis. The result also depends on the particular benchmark estimate of trend-cycle adopted. Moreover, even if an additive adjustment were correct for any given year, common trends in the seasonal-irregular and trend-cycle would tend to produce significant regression slopes and a misleading indication of a multiplicative relationship. For a theoretical analysis of the potentialities of regression in estimating seasonality, see Michael C. Lovell, "Seasonal Adjustment of Economic Time Series and Multiple Regression Analysis," Journal of the American Statistical Association, vol. 58 (December 1963), pp. 993-1010.

9. For details, see John A. Brittain, "A Regression Model for Estimation of the Seasonal Component in Unemployment and Other Volatile Time Series," Review of Economics and Statistics, vol. 44 (February 1962), pp. 24-36. 
objective is not only to choose among the official, additive, and residual approaches, but also to derive from the data new series free of the hypothesized bias. The model uses the following symbols:

$$
\begin{aligned}
y= & \text { original observation } \\
t_{0} c_{0} i_{0}= & \text { product of trend, cycle, and irregular components derived from } \\
& \text { standard model } \\
t_{1} c_{1} i_{1}= & \text { product of trend, cycle, and irregular components derived from } \\
& \text { proposed model } \\
s_{0}= & \text { standard seasonal factor } \\
x_{0}= & \text { standard estimate of seasonally adjusted rate } \\
x_{1}= & \text { proposed estimate of seasonally adjusted rate } \\
\bar{x}= & \text { unknown true value of the seasonally adjusted rate } \\
m= & \text { mean level of series in interval over which } s_{0} \text { is computed } \\
r= & \bar{x} / m .
\end{aligned}
$$

The traditional model relating each observation to its components is

$$
y=t_{0} c_{0} s_{0} i_{0} .
$$

This model was generalized to allow the seasonal factor to vary with the level of the series:

$$
y=t_{1} c_{1} S_{0}^{1+b} \log r i_{1} .
$$

This particular specification of the seasonal factor was designed, first of all, to test a hypothesis about the relation between the standard adjusted series $\left(x_{0}\right)$ and the standard seasonal factor $\left(s_{0}\right)$, a relation that would not exist if the series were appropriately deseasonalized. However, the assumed relation is a complex one, varying in direction with the level of the series. The multiplicative seasonal correction is presumed to overadjust when the relative level of the series $(r)$ is "high" and underadjust when it is "low." Evidence of this would be a negative estimate of the coefficient $b$ in equation 2 . When $r$ is greater than one, the exponent of the seasonal factor is negative-yielding a seasonal factor closer to unity, and a smaller relative correction. When unemployment is relatively low, the exponent is positive and the factor further from unity.

The second objective of the model was to derive a new series uncorrelated with the seasonal-amplitude variable. Dividing $y$ by the official and proposed seasonal factors yields the official and alternative adjusted series, 
$x_{0}$ and $x_{1}$, and the relation between them:

$$
x_{1}=x_{0} s_{0}^{-b \log r} \text {. }
$$

This relation is the basis of an iterative procedure yielding a new series, $x_{1}$, that is free of the bias expected in $x_{0}$.

\section{Estimation of $\boldsymbol{b}$ and $x_{1}$}

The focus was on the relationship between the officially adjusted series, $x_{0}$, and the seasonal-amplitude variable, $\log s_{0} \log r$. Division of equation 2 by the official seasonal factor and the logarithmic transformation yield an expression for the official adjusted series:

$$
\log x_{0}=\log \left(t_{1} c_{1}\right)+b \log s_{0} \log r+\log i_{1} .
$$

Estimation of $b$ from 4 is hampered by the absence of reliable measures of $t_{1} c_{1}$ and of $r=\bar{x} / m$. The $t_{1} c_{1}$ was combined with $i_{1}$ in an error term, $u_{1}$. First differences were used to wash out some of the effects of trend and cycle and to focus on month-to-month changes. A constant term was included to accommodate any linear trend. ${ }^{10}$ This yields the estimating equation:

$$
\Delta \log x_{0}=a+b \Delta \log s_{0} \log r+\Delta u_{1} .
$$

The problem of the unknown $r=\bar{x} / m$ was two-fold. First, it was necessary to estimate $m$-the average level for the interval over which each seasonal factor was computed. The approach here followed the averaging and weighting scheme used in deriving the official seasonal factors. ${ }^{11}$ Second, the difficulty of the unknown "true" adjusted value $\bar{x}$ was approached by iteration. The objective was a new series free of the type of bias described. This would be evidenced by $b=0$, after successive substi-

10. The basic difficulty in estimating $b$ is the large variance of $\log x_{0}$ obviously associated with the unknown trend and cycle components and only slightly influenced by the short-run bias of interest here. One approach to this problem is a regression on first differences designed to reduce serial correlation of the errors, blunt the influence of trend and cycle, and reveal short-term behavior.

11. Basically, the official method uses centered twelve-month moving averages of the raw series, dividing each observation by the moving average and estimating seasonal factors as a weighted average of these ratios over several years. The estimates of $m$ used here apply the same weights to the moving average itself. 
tutions of new series for the official series in equation 5. The latter relation was fitted first with $x_{0}, s_{0}$, and $r=x_{0} / m$ as the first approximations. The first approximation of $x_{1}$ was then derived from relation 3 , using the estimated $b$ along with the official series from which it was derived by 5 . The new $x_{1}, s_{1}$, and $x_{1} / m$ were substituted into 5 to derive the second approximation of $b$. The second approximation of $x_{1}$ was then derived by substitution in 3 , and so on, until $b$ was close to zero.

This last estimate of $x_{1}$ was assumed to be unbiased, at least to the extent that it was uncorrelated with the seasonal-amplitude variable $\log s_{0}$ $\log r$.

\section{Empirical Findings}

Estimates were derived for periods beginning with 1948 and with 1967, and several possible empirical qualifications were considered.

\section{RESULTS BEGINNING WITH 1948}

Official estimates were available in a continuous series of 338 monthly observations beginning with 1948 and ending with February 1976. ${ }^{12}$ These first estimates take advantage of all the observations, but the results shown in the next section are confined to the period beginning with 1967, when the official X-11 method was installed and applied fairly consistently. Estimates of equation 5 , with iterations, are given in table 2 . The significant negative coefficients in the first approximation support the hypothesis of overadjustment of the official series when unemployment is high and underadjustment when it is low.

The two best estimates of the proposed adjusted series $x_{1}$ were those yielding the fourth regressions in table 2 . Substitution of each series and its implied seasonal for $x_{0}$ and $s_{0}$ in 5 produced these estimates of $b$ at 0.02 and 0.03 -close enough to zero to suggest that the adjusted series had been purged of the seasonal component afflicting the official series. Whatever the accuracy of these series in other respects, they are at least uncorrelated with the seasonal-amplitude variable, $\log s_{1} \log \left(x_{1} / m\right)$.

12. Although changes in the official method occurred over this interval, and some components were adjusted additively, the method remained essentially multiplicative. 
Table 2. Regression Results for Equation 5, Applied with Iteration to the Official Unemployment Rate, January 1948-February 1976

\begin{tabular}{|c|c|c|c|c|c|c|c|c|}
\hline \multirow[b]{2}{*}{$\begin{array}{l}\text { Approx- } \\
\text { imation } \\
\text { of } b\end{array}$} & \multicolumn{4}{|c|}{$\begin{array}{l}\text { No correction for } \\
\text { autocorrelation }\end{array}$} & \multicolumn{4}{|c|}{$\begin{array}{c}\text { First-order correction for } \\
\text { autocorrelation }\end{array}$} \\
\hline & $\begin{array}{c}\text { Coefficient } \\
b \\
\end{array}$ & $\begin{array}{c}t- \\
\text { statistic }\end{array}$ & $\bar{R}^{2}$ & $\begin{array}{l}\text { Durbin- } \\
\text { Watson } \\
\text { statistic }\end{array}$ & $\begin{array}{c}\text { Coefficient } \\
b \\
\end{array}$ & $\begin{array}{c}t- \\
\text { statistic }\end{array}$ & $\bar{R}^{2}$ & $\begin{array}{l}\text { Durbin- } \\
\text { Watson } \\
\text { statistic }\end{array}$ \\
\hline First & -1.09 & -3.79 & 0.038 & 1.52 & -1.35 & -5.06 & 0.107 & 2.13 \\
\hline Second & 0.33 & 1.12 & 0.001 & 1.54 & 0.46 & 1.67 & 0.077 & 2.13 \\
\hline Third & -0.08 & -0.27 & $\ldots$ & 1.53 & -0.12 & -0.41 & 0.065 & 2.13 \\
\hline Fourth & 0.02 & 0.07 & $\ldots$ & 1.54 & 0.03 & 0.11 & 0.066 & 2.13 \\
\hline
\end{tabular}

Source: Derived from text equations 3 and 5 using the latest revised data for the unemployment rate as of March 1976, provided by the U.S. Bureau of Labor Statistics, and the iteration method described in the preceding section of the text.

Changes in the two derived series $x_{1}$ are compared in table 3 with changes in the official and alternative adjusted rates. The $x_{1}$ series with and without correction for autocorrelation do not differ much from each other, but both differ consistently in the expected way from the official series. The comparisons selected were for months of high seasonality and unemployment. In those circumstances, the official series overstates the change between months of low (high) and high (low) seasonal unemployment. During the 1949-50, 1953-54, and 1957-58 recessions, the revised series generally show less than half the changes indicated by the official series. ${ }^{13}$ For the current recession the revised series show somewhat more than half the changes appearing in the official figures.

The estimates presented above and those to follow are subject to qualifications concerning errors in the model, the missing trend-cycle variable, and possible spurious association due to the presence of the adjusted series on both sides of equation 5 . These are considered briefly in the appendix, but no serious estimating difficulty was apparent.

\section{RESULTS BEGINNING WITH 1967}

The adjustments before 1967 were based on a multiplicative model and process somewhat different from the X-11 program applied since then. It

13. Similar discrepancies were found in the original official estimates for the 1960-61 recession. (See Brittain, "Regression Model," p. 28.) However, subsequent revision erased the indicated bias, since 1960-61 unemployment was no longer substantially higher than the weighted average of the seven-year interval on which the seasonal factors were based. 
Table 3. Comparison of Estimated Changes in Alternative Adjusted Unemployment Rates, Selected Periods of Relatively High Unemployment, 1949-76

Percentage points

\begin{tabular}{|c|c|c|c|c|}
\hline \multirow[b]{2}{*}{ Period } & \multirow[b]{2}{*}{ Official } & \multirow[b]{2}{*}{$\begin{array}{c}\text { Additive } \\
\text { or } \\
\text { residual }\end{array}$} & \multicolumn{2}{|c|}{ New estimates, $x_{1}$} \\
\hline & & & $\begin{array}{l}\text { Uncorrected } \\
\text { for auto- } \\
\text { correlation }\end{array}$ & $\begin{array}{c}\text { Corrected } \\
\text { for auto- } \\
\text { correlation }\end{array}$ \\
\hline July-October 1949a & 1.2 & b & 0.66 & 0.53 \\
\hline October 1949a-February 1950 & -1.5 & b & -0.79 & -0.62 \\
\hline February-October 1954 & 0.5 & b & 0.25 & 0.19 \\
\hline February-October 1958 & 0.3 & b & 0.11 & 0.06 \\
\hline February-October 1975 & 0.6 & 0 & 0.39 & 0.35 \\
\hline October 1975-February 1976 & -1.0 & -0.5 & -0.82 & -0.77 \\
\hline
\end{tabular}

Sources: The basic data are from "Statement of Julius Shiskin," and tabulations provided by the Bureau of Labor Statistics. The new estimates are derived from text equations 3 and 5 as described in table 2.

a. The Bureau of Labor Statistics reported that its unadjusted rate for this date is too high due to incorrect classification of striking coal miners, but the contrast in seasonal adjustments is no less meaningful.

b. Official estimates of these alternatives for this period are not available.

seemed appropriate to duplicate the estimates for this shorter period with these 110 more consistently estimated observations. This period is also convenient for analysis of the additive and residual alternatives which have been recently computed by the BLS for the period beginning with 1967 .

Table 4 reports the results for this later period, duplicating the approach taken in table 2. The results for the two periods agree closely, and show the same bias in the official series. This is remarkable, given that the official method has changed, only one-third as many observations are available, and there was no sharp increase in unemployment until recently.

Table 5 presents results of the same approach applied to the additive and residual alternatives. ${ }^{14}$ The positive first coefficient for the additive adjustment is of marginal significance; it suggests a tendency to underadjust when unemployment is high, in contrast with the multiplicative model which was found to overadjust. The coefficient $b$ for the residual model is near zero, indicating no appreciable bias. However, the standard error, at 0.52 , is considerably higher than that for the other methods, and the 95 percent confidence interval for $b$ is rather wide, -1.12 to +0.92 .

The implications of these results are illustrated in table 6. First is the remarkable agreement between rates based on the official multiplicative

14. These alternative series and their implied seasonal factors were substituted for $x_{0}$ and $s_{0}$, respectively, in equation 5 . The same iteration procedure applied to $x_{0}$ and described in detail in the text was carried out for them. 
Table 4. Regression Results for Equation 5, Applied with Iteration to the Official Unemployment Rate, January 1967-February 1976

\begin{tabular}{|c|c|c|c|c|c|c|c|c|}
\hline \multirow[b]{2}{*}{$\begin{array}{l}\text { Approx- } \\
\text { imation } \\
\text { of } b\end{array}$} & \multicolumn{4}{|c|}{$\begin{array}{l}\text { No correction for } \\
\text { autocorrelation }\end{array}$} & \multicolumn{4}{|c|}{$\begin{array}{l}\text { First-order correction for } \\
\text { autocorrelation }\end{array}$} \\
\hline & $\begin{array}{c}\text { Coefficient } \\
\quad b\end{array}$ & $\begin{array}{c}t- \\
\text { statistic }\end{array}$ & $\bar{R}^{2}$ & $\begin{array}{l}\text { Durbin- } \\
\text { Watson } \\
\text { statistic }\end{array}$ & $\begin{array}{c}\text { Coefficient } \\
b\end{array}$ & $\begin{array}{c}t- \\
\text { statistic }\end{array}$ & $\bar{R}^{2}$ & $\begin{array}{l}\text { Durbin- } \\
\text { Watson } \\
\text { statistic }\end{array}$ \\
\hline Fir & -1.25 & -3.13 & 0.075 & 1.15 & -1.10 & -3.15 & 0.241 & 2.16 \\
\hline Second & 0.01 & 0.01 & $\ldots$ & 1.15 & 0.00 & 0.01 & 0.173 & 2.16 \\
\hline
\end{tabular}

Sources: Same as table 2 .

model and those based on the additive model applied to the overall unemployment rate, after revision to remove bias. The maximum difference between the two is 0.08 point, which could easily be due to rounding since each rate is published to the nearest tenth of a point. The revised additive series shows changes in the rate somewhat smaller than those of the revised official rate and much smaller than those in the official rate itself. In all three intervals it is closer to the raw additive series than to the official rate.

Since no appreciable evidence of bias appeared in the residual rate, the revised version for each period shown in table 6 differs by only 0.01 from the raw computed value. The revised residual rate suggests a bias in the official rate of about one-half a percentage point in all three intervals of change reported in table 6 . This finding is qualified by the underlying 0.52 standard error of $b$.

The accuracy of the residual estimate can be appraised in terms of a 95

Table 5. Regression Results for Equation 5, Applied with Iteration to the Additive and Residual Unemployment Rates, January 1967-February 1976

\begin{tabular}{|c|c|c|c|c|c|c|c|c|}
\hline \multirow[b]{2}{*}{$\begin{array}{l}\text { Approx- } \\
\text { imation } \\
\text { of } b\end{array}$} & \multicolumn{4}{|c|}{ Additive } & \multicolumn{4}{|c|}{ Residual } \\
\hline & $\begin{array}{c}\text { Coefficient } \\
b\end{array}$ & $\begin{array}{c}t- \\
\text { statistic }\end{array}$ & $\bar{R}^{2}$ & $\begin{array}{l}\text { Durbin- } \\
\text { Watson } \\
\text { statistic }\end{array}$ & $\begin{array}{c}\text { Coefficient } \\
b\end{array}$ & $\begin{array}{c}t- \\
\text { statistic }\end{array}$ & $\bar{R}^{2}$ & $\begin{array}{l}\text { Durbin- } \\
\text { Watson } \\
\text { statistic }\end{array}$ \\
\hline First & 0.66 & 1.81 & 0.134 & 2.11 & -0.10 & -0.18 & . & 2.06 \\
\hline Second & -0.01 & -0.04 & 0.113 & 2.11 & -0.00 & -0.00 & $\ldots$ & 2.06 \\
\hline
\end{tabular}

Sources: Based on regressions from text equation 5 and the iteration method described in the text. The data used for the additive series are unpublished estimates of the unemployment rate by the additive method. The residual is the difference between the official adjusted employment series and the unpublished X-11 adjustment of the labor force. All basic data were supplied by the Bureau of Labor Statistics. Beginning with 1975 , the figures underlying this table differ slightly from those in table 1 because the longer series were revised less recently. 
Table 6. Comparison of Various Estimates of Levels and Changes of the Unemployment Rate, 1975-76

\begin{tabular}{|c|c|c|c|c|c|c|c|c|}
\hline \multirow[b]{2}{*}{ Period } & \multicolumn{3}{|c|}{ Official adjusted } & \multicolumn{2}{|c|}{$\begin{array}{l}\text { Unofficial } \\
\text { adjusted }^{\mathrm{a}}\end{array}$} & \multicolumn{3}{|c|}{ Revised to remove bias ${ }^{\mathrm{b}}$} \\
\hline & $\begin{array}{l}\text { Offi- } \\
\text { cial }\end{array}$ & $\begin{array}{l}\text { Addi- } \\
\text { tive }\end{array}$ & $\begin{array}{l}\text { Resid- } \\
\text { ual }\end{array}$ & $\begin{array}{l}\text { Addi- } \\
\text { tive }\end{array}$ & $\begin{array}{l}\text { Resid- } \\
\text { ual }\end{array}$ & $\begin{array}{l}\text { Offi- } \\
\text { cial }\end{array}$ & $\begin{array}{l}\text { Addi- } \\
\text { tive }\end{array}$ & $\begin{array}{c}\text { Resid- } \\
\quad \text { ual }\end{array}$ \\
\hline 1975 & \multicolumn{8}{|c|}{ Level (percent) } \\
\hline February & 8.0 & 8.4 & 8.4 & 8.3 & 8.35 & 8.15 & 8.23 & 8.36 \\
\hline May & 8.9 & 8.7 & 8.7 & 8.7 & 8.75 & 8.79 & 8.74 & 8.74 \\
\hline October & 8.6 & 8.4 & 8.4 & 8.4 & 8.33 & 8.49 & 8.45 & 8.32 \\
\hline 1976 & & & & & & & & \\
\hline February & 7.6 & 7.9 & 7.9 & 7.8 & 7.83 & 7.72 & 7.73 & 7.84 \\
\hline 1975 & \multicolumn{8}{|c|}{ Change (percentage points) } \\
\hline $\begin{array}{c}\text { February to } \\
\text { May }\end{array}$ & 0.9 & 0.3 & 0.3 & 0.4 & 0.40 & 0.64 & 0.51 & 0.38 \\
\hline $\begin{array}{c}\text { February to } \\
\text { October }\end{array}$ & 0.6 & 0.0 & 0.0 & 0.1 & -0.02 & 0.34 & 0.22 & -0.04 \\
\hline $\begin{array}{l}1975-76 \\
\text { October to }\end{array}$ & & & & & & & & \\
\hline February & -1.0 & -0.5 & -0.5 & -0.6 & -0.50 & -0.77 & -0.72 & -0.48 \\
\hline
\end{tabular}

Sources: Official adjusted, same as table 1; unofficial, same as table 5; revised, official-based on computations underlying table 4; revised, additive and residual-based on computations underlying table 5 .

a. These derived additive and residual series differ slightly from the later official figures at their left because the latter have been more recently revised.

b. These series are unbiased in the sense that each variant of proposed series $x_{1}$ is uncorrelated with $\log s_{1} \log \left(x_{1} / m\right)$, where $s$ is the revised seasonal factor and $m$ is the mean level of the series in the period over which the official seasonal factor was estimated.

confidence interval based on the standard error of $b$ and application of relation 3. The largest difference between the revised residual and official rates was 0.36 point in February 1975. The 95 percent confidence interval is 8.25 to 8.47 percent..$^{15}$ The adjusted additive estimate, which is also subject to substantial error, is, at 8.23 , just outside that range.

In sum, the removal of bias from the official and additive series yields two new series that check closely. The original residual series showed no appreciable bias. However, that finding should be treated as tentative in light of the agreement between the other two, corrected, series. The residual serves as an acceptable alternative to these two; the differences among them could easily be due to sampling error. In any case, all three appear more reliable than the biased official series.

15. This confidence belt takes account only of the error in $b$ as a measure of the undesired relationship between the series and the variable seasonal factor. No other sampling or measurement error is covered. 


\section{Conclusion}

Throughout the postwar period, the official multiplicative models appear consistently to have overadjusted for seasonality when unemployment was high. This bias does not seem serious under normal conditions, but during recessions it can paint a misleading picture of month-to-month changes. The residual estimate still appears to be an adequate, unbiased substitute, but it need not serve by itself. As shown, the official and additive series can be purged of their biases.

Allowance for variation of the amplitude of seasonal factors appears to be appropriate, but that can be achieved more directly than by relying on the additive or residual models, which are special cases. The nature of this variation should be estimated from the data, as attempted here. No claim is made that the present approach is optimal; certainly, the estimation procedure should be more efficient. Nevertheless, the present evidence strongly supports an approach that allows the amplitude of seasonal factors to vary with the level of the series-especially if the series is a volatile one.

\section{APPENDIX \\ Tests of Some Potential Qualifications}

THE FIRST-DIFFERENCE approach in equation 5 produced manageable autocorrelation which was reduced further by the first-order correction. An alternative and possibly more efficient approach would be to include the trend-cycle component, as in equation 4 , before differencing. This method did not seem promising, because at the outset no reliable estimate was available. Nevertheless, for one test of the stability of estimates of $b$, the twelve-month moving average was included as an estimate of $t_{1} c_{1}$ in equation 4 before differencing. This moving-average variable was highly 
significant and improved the fit, but the estimates of $b$ and its standard error were not much affected. ${ }^{16}$

The structure of the amplitude variable itself is apt to raise suspicions. Whatever the measure of $\log r, \log x_{0}$ and $\log r$ obviously will be highly correlated. Such a correlation might suggest that the significant association observed between $\log x_{0}$ and the amplitude variable $\log s_{0} \log r$ could be meaningless, merely reflecting the obvious association of $x_{0}$ and $r$. This conclusion seems highly unlikely. ${ }^{17}$ Even so, it is worthwhile to try to estimate $b$ in such a way as to eliminate the possibility. One approach is a forecasting model that relates $\Delta \log x_{0}$ to $\Delta \log s_{0}$ and the given value of $\log r$ before each monthly change. Equation 5 was adapted this way to forecast the spurious change in $\log x_{0}$ due to the known change in the seasonal index alone. Again, no important change was obtained in $b$ or its standard error. The same was true when measures of $\bar{x}, m$, and $\log r$ were included separately in the model; the estimates of $b$ were unshaken:

16. More detailed analysis of errors in the model, including linearity, constant variance, and normality, was presented earlier. No serious difficulties were encountered. See Brittain, "Regression Model," pp. 34-35.

17. The estimates show that $\Delta \log x_{0}$ and $\Delta \log s_{0} \log r$ are negatively correlated, although $\Delta \log x_{0}$ and $\Delta \log r$ are positively correlated. It therefore seems reasonable to suppose that the association in question is due to a systematic relation between $x_{0}$ and $s_{0}$, rather than the positive association of $s_{0}$ and $r$. 